\title{
PENERAPAN IOT PADA MONITORING BUDIDAYA UDANG HIAS DALAM AKUARIUM BERBASIS ARDUINO
}

\author{
Wibis Finanda, Joseph Dedy Irawan, Karina Auliasari \\ Program Studi Teknik Informatika S1, Fakultas Teknologi Industri \\ Institut Teknologi Nasional Malang, Jalan Raya Karanglo km 2 Malang, Indonesia \\ Finanda.mlg00356@gmail.com
}

\begin{abstract}
ABSTRAK
Pada saat ini peminat udang hias sebagai binatang peliharaan sedang banyak peminat nya tetapi bagi sebagian orang dengan kepadatan aktifitas yang tinggi tidak dapat memelihara udang hias dengan baik sebagai contoh tidak dapat memberi makan udang tepat waktu, tidak dapat mengontrol keadaan air akuarium seperti ph air, kekeruhan air dan suhu, padahal hal tersebut sangan penting untuk tumbuh kembang udang hias.

Pembuatan alat ini melakukan penerapan iot pada monitoring aquarium berbasis arduino. Pada alat ini dapat membaca indikator yang berasal dari berbagai sensor yang terpasang didalamnya seperti indikator suhu air, kekeruhan serta $\mathrm{pH}$ air. Selain itu alat ini dapat memberikan pakan secara otomatis serta dapat menghidupkan dan mematikan perangkat yang terdapat pada akuarium seperti pompa, dan heater. Pada alat ini dapat bekerja secara sistem manual dan dipantau dengan Monitoring melalui smartphone.

Karena itu penerapan iot pada monitoring aquarium berbasis arduino menadi pilihan penulis untuk mengatasi masalah dalam permasalahan tersebut karena dapat mengatasi permasalahan yang ada dengan alat tersebut dengan menyetabilkan kadar ph dalam air, menyetabilkan suhu dan menjaga tingkat kejernihan air.
\end{abstract}

Kata Kunci : arduino, mikrokontroller, iot, embedded system

\section{PENDAHULUAN}

Pada saat ini peminat udang hias sebagai binatang peliharaan sedang banyak peminat nya tetapi bagi sebagian orang dengan kepadatan aktifitas yang tinggi tidak dapat memelihara udang hias dengan baik sebagai contoh tidak dapat memberi makan udang tepat waktu, tidak dapat mengontrol keadaan air akuarium seperti ph air,kekeruhan air dan suhu, padahal hal tersebut sangan penting untuk tumbuh kembang udang hias, oleh karena itu penulis ingin membuat alat untuk mempermudah pemilik udang hias agar dapat mengontrol akuarium agar kondisi selalu optimal untuk tumbuh kembang udang hias.

Perancangan dari penerapan iot pada monitoring aquarium berbasis arduino, dirancang agar dapat memberikan kemudahan terhadap para penghobi udang hias yang memelihara di dalam akuarium. Pada alat ini dapat membaca indikator yang berasal dari berbagai sensor yang terpasang didalamnya seperti indikator suhu air, kekeruhan serta $\mathrm{pH}$ air. Selain itu alat ini dapat memberikan pakan secara otomatis serta dapat menghidupkan dan mematikan perangkat yang terdapat pada akuarium seperti pompa, dan heater. Pada alat ini dapat bekerja secara sistem manual dan dipantau dengan Monitoring melalui smartphone. Tiap sensor yang ada pada perangkat smart aquarium bekerja dengan nilai tegangan berkisar $3 \mathrm{~V}$ sampai dengan $5 \mathrm{~V}$ pada tiap-tiap modul yang digunakan, sehingga perangkat dapat berjalan dengan baik dan dapat digunakan dengan baik.

\section{TINJAUAN PUSTAKA}

\subsection{Penelitian Terdahulu}

Ditahun 2018 Gentur dan kawan kawan membuat sebuah Project Optimasi Tingkat Hidup Udang Crystal Red dengan Menerapkan Metode Fuzzy Logic Berbasis IOT, Penelitian ini membuat sebuah sistem pemantauan dan pengendalian otomatis kualitas air menggunakan Fuzzy Inference System berbasis Internet of Things. Sistem ini menggunakan beberapa sensor antara lain suhu ruangan, suhu air, Dissolved Oxygen, dan turbidity. Sensor-sensor tersebut terhubung pada Raspberry pi 3 yang telah ditanam sebuah sistem menggunakan Fuzzy Inference System untuk mengontrol aktuator secara otomatis. Sistem real-time monitoring dapat diakses melalui Thingspeak dan juga MQTT. Dari hasil penelitian didapatkan nilai akurasi dari Real-time monitoring sebesar $97,93 \%$. Untuk prosentase keberhasilan dari sistem berdasarkan tingkat hidup adalah $90 \%$ Sedangkan pertumbuhan Crystal Red Shrimp selama 3 minggu dengan nilai rata-rata 2,191 atau $0,191 \mathrm{~cm}$ lebih optimal daripada yang melalui proses budidaya konvensional. [1]

Ditahun yang sama yudi dan kawan -kawan mengembangkan sistem online monitoring kualitas air berbasis wireless sensor Network (WSN) dan Internet of Things (IoT). Sistem ini didesain dan dikembangkan untuk memantau parameter DO (Dissolved Oxygen), $\mathrm{pH}$, conductivity dan temperatur pada budidaya udang. Sistem terdiri dari beberapa node sensor dengan komponen utama arduino uno yang terhubung dengan Xbee board dan master board dengan komponen utamanya adalah Raspberry Pi 2 (RPi2) board dan Xbee. Data dikirim dari masing- 
masing node ke RPi2 menggunakan jaringan WSN dengan paket data yang dilengkapi dengan masingmasing ID, setelah itu data disimpan di database internal RPi2 dan ditampilkan di graph. Timer update server digunakan untuk update data dari RPi2 ke server menggunakan jaringan internet melalui wifi. Data di server dapat dilihat menggunakan website, selain itu juga data dapat dilihat pada aplikasi Telegram Messenger yang ter-install di perangkat ponsel. Program RPi2 dikembangkan menggunakan bahasa python dan komponen matplotlib. Hasil percobaan menunjukkan bahwa sistem memiliki prospek yang besar dan dapat digunakan untuk keperluan budidaya udang dengan memberikan informasi yang relevan dan tepat waktu. Data hasil pengumpulan tersebut dapat digunakan untuk penelitian dan analisa lebih lanjut. [2]

Gian di tahun 2017 mengembangkan rancang bangun web server untuk pemantauan budidaya udang vannamei menggunakan teknologi iot. Upaya yang dilakukan untuk meningkatkan minat masyarakat membudidayakan Udang yaitu mengembangkan budidaya tersebut dengan website berbasis IoT, dimana website ini terhubung dengan sistem mikrokontroler, melalui platform firebase. Web tersebut memiliki fitur yang penting dalam pertambakan, diantaranya petambak bisa lebih mudah mengontrol ph air, suhu air status pakan dan pemberian pakan secara manual. Hasil pengujian Subyektif didapat hasil 4,12 dari skala 1 sampai 5, maka performasi aplikasi Web Server Budidaya Udang ini masuk kategori Cukup Baik. Sedangkan pada pengujian Konektivitas terdapat delay Monitoring ph 1,42 detik, monitoring Suhu 1,17 detik, monitoring Status Pakan 1,14 detik, controling On/Off 1,21 detik, controling Pakan Bulanan 1,03 detik dan controling Pakan Harian 1,05 detik. [3]

Pada tahun 2019 Ridwan mengembangkan Peningkatan Budidaya Udang Galah Melalui Pemantauan dan Pengendalian Kualitas Air Secara Otomatis Berbasis IoT. Ridwan mengusulkan sistem pemantau dan pengendalian kualitas air secara otomatis meliputi DO, suhu dan $\mathrm{pH}$ air dengan dengan mikrokontroler secara real time berbasis Internet of Things yang diintegrasikan dengan website dan aplikasi pada smartphone. Sistem ini juga dilengkapi dengan aerotor, pompa cairan basa, sistem pemanas dan pendingin air. Berdasarkan pengukuran dan simulasi sistemselama satu bulan dengan udang Galah, sistem dapat menjaga suhu air pada rentang 25 -27 derajat celcius, $\mathrm{pH}$ air $6,8-7,5$ dan kadar Oksigen 5-7 mg/L dengan menghasilkan survival rate 90 persen pada padat tebar 20 ekor udang dengan luas media pembesaran 0,32 $\mathrm{m} 2$. [4]

Kemudian di tahun 2019 Dista dan kawan kawan juga mengembangkan Sistem Monitoring $\mathrm{pH}$ dan Kekeruhan pada Akuarium Air Tawar. Sistem ini dibangun menggunakan komponen opensource dan sensor berbiaya rendah. Data monitoring digunakan untuk mengaktifkan aktuator berupa filter air. Filter akan aktif apabila tingkat kekeruhan air sudah melebihi batas kekeruhan yang ditentukan. Pengujian kekeruhan air aquarium menunjukkan saat kekeruhan mencapai 3000 ntu pukul 14.12 pompa aktif dan filter bekerja sampai kekeruhan berada pada nilai $498 \mathrm{ntu}$ pada pukul 17.00 dan pompa mati secara otomatis. Nilai $\mathrm{pH}$ dan kekeruhan air berhasil ditampilkan dengan baik di aplikasi Blynk pada ponsel. [5]

\subsection{Arduino}

Arduino adalah pengendali mikro single-board yang bersifat sumber terbuka, diturunkan dari Wiring platform, dirancang untuk memudahkan penggunaan elektronik dalam berbagai bidang. Perangkat kerasnya memiliki prosesor Atmel AVR dan softwarenya memiliki bahasa pemrograman sendiri. Arduino juga merupakan senarai perangkat keras terbuka yang ditujukan kepada siapa saja yang ingin membuat purwarupa peralatan elektronik interaktif berdasarkan hardware dan software yang fleksibel dan mudah digunakan. Mikrokontroler diprogram menggunakan bahasa pemrograman arduino yang memiliki kemiripan syntax dengan bahasa pemrograman C. Karena sifatnya yang terbuka maka siapa saja dapat mengunduh skema hardware arduino dan membangunnya. Arduino menggunakan keluarga mikrokontroler ATMega yang dirilis oleh Atmel sebagai basis, namun ada individu/perusahaan yang membuat clone arduino dengan menggunakan mikrokontroler lain dan tetap kompatibel dengan arduino pada level hardware. Untuk fleksibilitas, program dimasukkan melalui bootloader meskipun ada opsi untuk mem-bypass bootloader dan menggunakan pengunduh untuk memprogram mikrokontroler secara langsung melalui port ISP.

\subsection{Sensor Suhu DS18B20}

Sensor ini merupakan sensor suhu DS18B20 dengan kemampuan tahan air (waterproof) sehingga cocok digunakan untuk mengukur suhu pada tempat yang sulit, atau basah. DS18B20 menyediakan 9 hingga 12-bit (yang dapat dikonfigurasi) data. Sensor menggunakan Chip DS18B20. Struktur sensor ini adalah berujung stainless steel, anti karat dan tahan air (waterproof). Sensor ini biasa digunakan untuk mengukur suhu akuarium, suhu air mendidih dan sebagainya. sensor ini memiliki fitur utama sebagai berikut, Antarmuka hanya menggunakan satu kabel sebagai komunikasi (menggunakan protokol Unique 1-Wire), Setiap sensor memiliki kode pengenal unik 64-bit yang tertanam di onboard ROM, Kemampuan multidrop yang menyederhanakan aplikasi penginderaan suhu terdistribusi, Tidak memerlukan komponen tambahan Juga bisa diumpankan daya melalui jalur datanya.

\subsection{Sensor ph air}

Modul sensor ini merupakan module yang berfungsi untuk mendeteksi tingkat ph air yang dimana outputnya berupa tegangan analog. Sehingga 
untuk mengkonversi nilai pembacaan harus dimasukan ke dalam rumus di kode program yang dibuat. Dikarenakan module ph meter sensor ini range output tegangan analognya dari $0-3 \mathrm{Vdc}$ dengan inputan power supply $3.3-5.5 \mathrm{Vdc}$. Modul ini memiliki Dua alat yang terpisah yaitu $\mathrm{pH}$ signal Conversion Board yang memiliki Spesifikasi Tegangan kerja antara $3.3 \sim 5.5 \mathrm{~V}$, Output tegangan analog : $0 \sim 3.0 \mathrm{~V}$, Jenis konektor probe yang digunakan tipe "BNC", Tingkat akurasi pengukuran : \pm 0.1 (pada suhu pengujian $25^{\circ} \mathrm{C}$ ), Signal Connector : PH2.0-3P,Dimensi board : 42mm x 32mm Dan Probe $\mathrm{pH}$ yang memiliki spesifikasi termasuk dalam grade laboratorium

\subsection{Sensor Turbidity}

Analog Turbidity Sensor For Arduino merupakan sensor yang berfungsi mengukur kualitas air dengan mendeteksi tingkat kekeruhannya. Sensor ini mendeteksi partikel tersuspensi dalam air dengan cara mengukur transmitansi dan hamburan cahaya yang berbanding lurus dengan kadar Total Suspended Solids (TTS). Semakin tinggi kadar TTS, maka semakin tinggi pula tingkat kekeruhan air tersebut. Sensor ini mendukung dua mode output, digital dan analog sehingga dapat dengan mudah diakses melalui Arduino atau mikrokontroler lainnya. Sensor ini dapat diaplikasikan untuk mengukur tingkat kekeruhan air pada sungai, danau, laboraturium, limbah cair, dsb. Fitur dari modul sensor kekeruhan air Berfungsi untuk mendeteksi kualitas air yaitu mengukur tingkat kekeruhan, Kompitibel dengan mikrokontroler terutama dengan arduino, Memiliki kemampuan mendeteksi suspended particles dalam air dengan mengukur transmisi cahaya dan tingkat hamburan yang dikonversi kedalam satuan Nephelometric Turbidity Unit (NTU)

\section{METODE PENELITIAN}

\subsection{Desain Arsitektur Sistem}

dalam desain arsitektur sistem terdapat tiga tahap yaitu input, proses, dan output seperti yang ada di gambar 1 di bawah ini

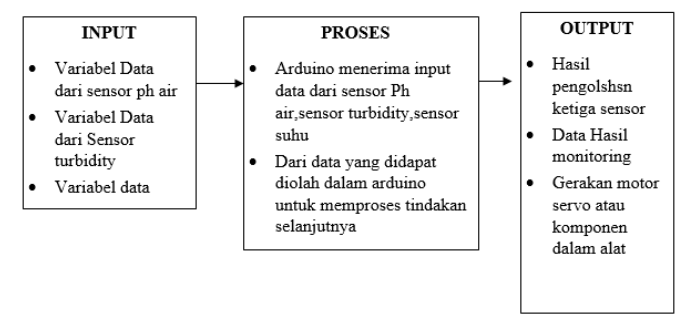

Gambar 1 Arsitektur sistem

\subsection{Desain Rangkaian}

Perangkat yang digunakan meliputi Arduino uno, sensor ph air, sensor turbidity, sensor suhu, motor servo esp8266 dan Relay

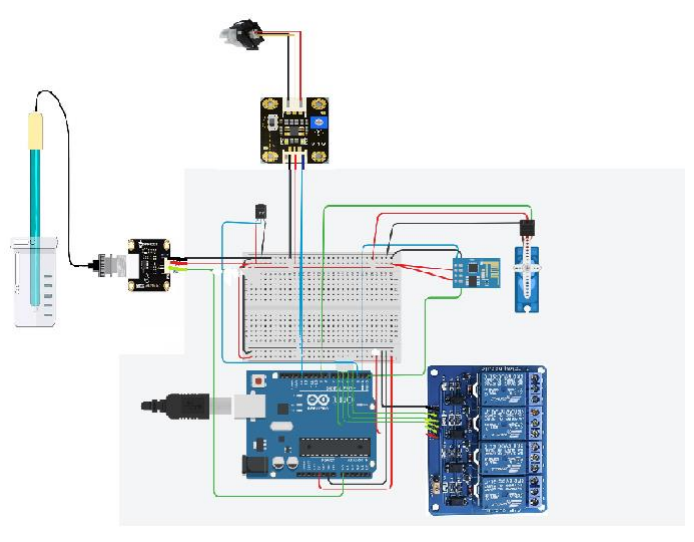

Gambar 2 Desain Rangkaian

\subsection{Flowchart Sistem}

Flowchart sistem ini menjelaskan proses berjalananya aplikasi seperti ditunjukkan pada Gambar 3.

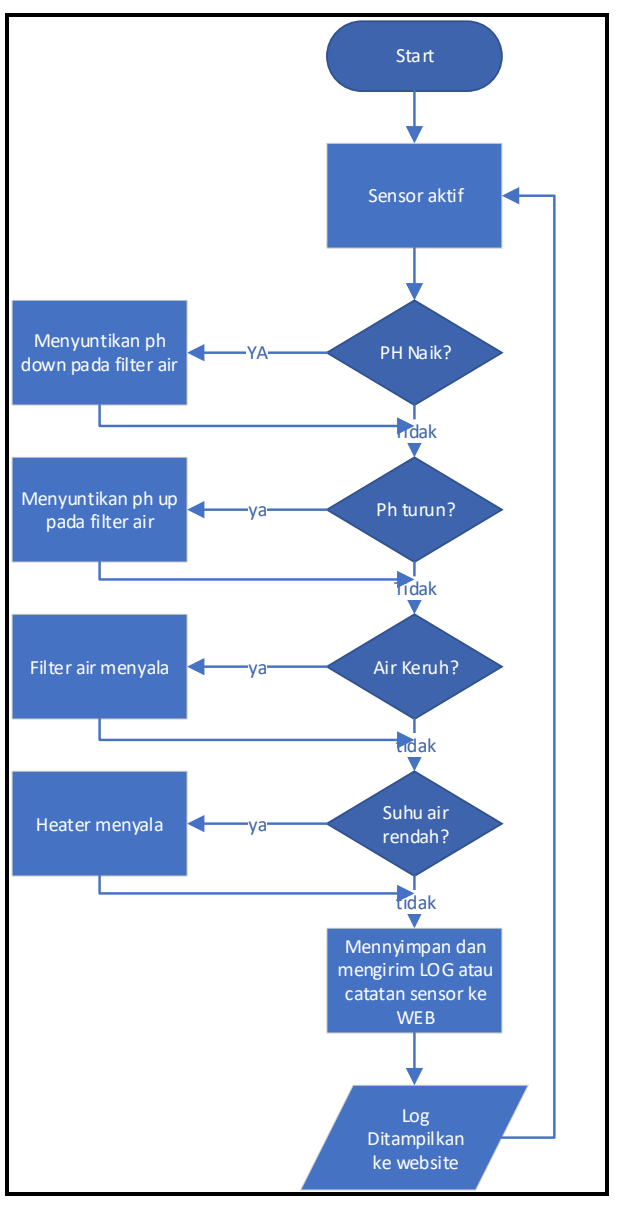

Gambar 3 Flowchart Sistem

Berdasarkan flowchart pada Gambar 3, sistem dimulai dari sensor aktif dan melakukan pembacaan data ph air apakah ph air naik jika bernilai true maka alat akan menginput cairan ph down pada akuarium jika tidak sensor akan membaca apakah ph air turun 
jika bernilai true akan menginputkan cairan ph up pada akuarium bila tidak akan berlanjut ke sensor turbidity,bila pembacaan sensor menyatakan keadaan air keruh maka filter akan menyala dan yang terakhir apakah suhu akuarium rendah bila bernilai true maka heater akan menyal semua data pembacaan sensor akan di kirim ke database dengan esp8266, dan akan berakhir apabila sumber listrik di lepas.

\section{HASIL DAN PEMBAHASAN}

\subsection{Pengujian Hardware}

Pengujian komponen dari Alat yang sudah terkoneksi meliputi sensor suhu, Arduino uno, Esp 8266-01, sensor ph air, sensor turbidity, sudah berhasil terkoneksi dengan database sehingga dapat dilakukan pertukaran data antara database dan esp 8266-01 Adapaun implementasi hardware ditunjukkan pada Gambar 4

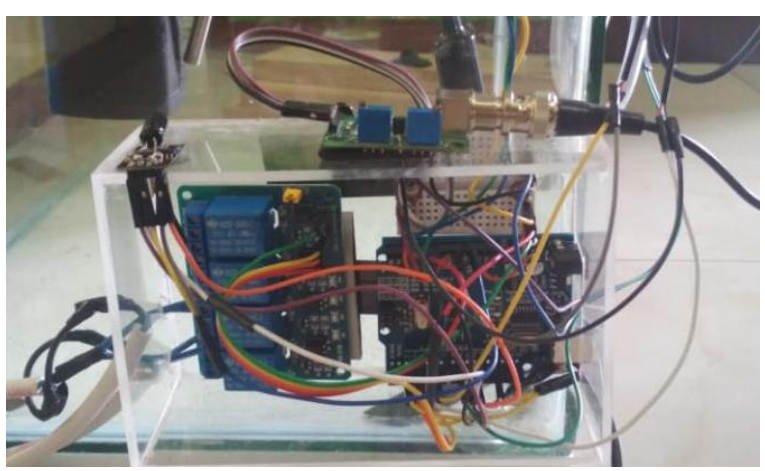

Gambar 4 Implementasi alat pada akuarium

Gambar 4 merupakan alat dari akuarium yang sudah berhasil terkoneksi dengan database untuk melakukan pertukaran data.

\subsection{Pengujian esp8266-01}

Pengujian menggunakan Esp8266-01 bertujuan menguji pengiriman data antara Arduino dan database. Sensor-sensor yang di uji bertujuan untuk mengetahui pembacaan dari sensor tersebut, Skema rangkaian alat beserta ditunjukkan pada Gambar 5

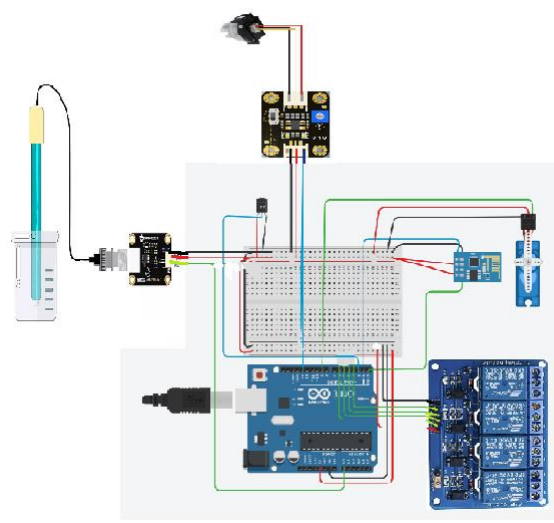

Gambar 5 Rangkaian sensor
Gambar 5 Merupakan diagram blok atau gambar rangkaian dari sensor dan Arduino yang telah di lakukan dan telah berhasil di dikirim ke database. Hasil pembacaan sensor dapat dilihat pada gambar 6 .

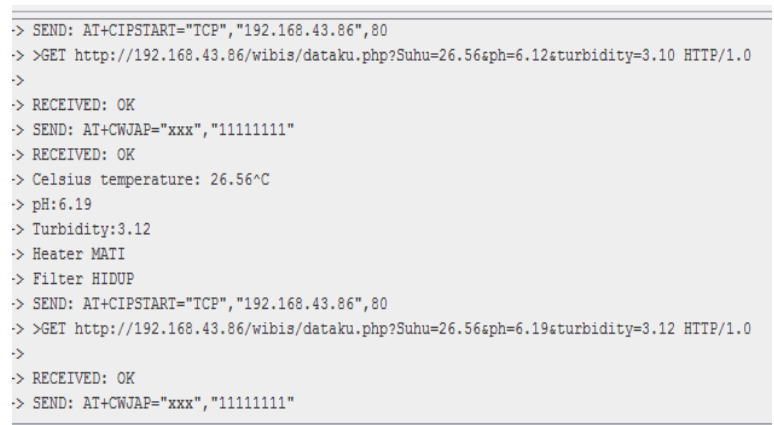

Gambar 6 Pembacaan sensor dan esp

Pada gambar 6 menunjukkan pengujian pengiriman data hasil deteksi sensor menggunakan Esp8266 , data sensor tersebut kemudian disimpan ke dalam database menggunakan Bahasa pemrograman php ke url 192.168.43.86/wibis/dataku.php data hasil uji dapat di lihat pada table 1

Tabel 1 Pengujian Komunikasi dan pengiriman data

\begin{tabular}{|c|c|c|c|}
\hline $\begin{array}{c}\text { Pengiriman } \\
\text { ke }\end{array}$ & $\begin{array}{c}\text { Terhubung Ke } \\
\text { AP }\end{array}$ & $\begin{array}{c}\text { Terhubung ke } \\
\text { Server }\end{array}$ & $\begin{array}{c}\text { Data Sukses } \\
\text { Dikirim }\end{array}$ \\
\hline 1 & Ya & Ya & Ya \\
\hline 2 & Ya & Ya & Ya \\
\hline 3 & Tidak & Tidak & Tidak \\
\hline 4 & Ya & Tidak & Tidak \\
\hline 5 & Ya & Ya & Ya \\
\hline 6 & Ya & Ya & Ya \\
\hline 7 & Ya & Ya & Ya \\
\hline 8 & Ya & Ya & Ya \\
\hline 9 & Ya & Ya & Ya \\
\hline 10 & Ya & Ya & Ya \\
\hline
\end{tabular}

\subsection{Pengujian Waterpump}

Pengujian Water pump dilakukan dengan cara memprogram Arduino sehingga dapat memerintahkan water pump agar memompa air untuk menanggapi hasil dari sensor ph, Pengujian penerapan pada konsep monitoring untuk kendali ph down dan ph up mendapatkan data sebagai berikut

Tabel 2 Pengujian waterpump "Ph Down"

\begin{tabular}{|c|c|c|}
\hline No & $\begin{array}{c}\text { Hasil deteksi } \\
\text { sensor Ph }\end{array}$ & $\begin{array}{c}\text { Waterpump Ph } \\
\text { Down }\end{array}$ \\
\hline 1 & 9.35 & $\mathrm{X}$ \\
\hline 2 & 9.35 & $\mathrm{X}$ \\
\hline 3 & 9.35 & $\checkmark$ \\
\hline 4 & 9.39 & $\checkmark$ \\
\hline 5 & 9.38 & $\checkmark$ \\
\hline 6 & 9.00 & $\checkmark$ \\
\hline 7 & 8.93 & $\checkmark$ \\
\hline 8 & 9.33 & $\checkmark$ \\
\hline 9 & 9.35 & $\checkmark$ \\
\hline 10 & 9.30 & $\checkmark$ \\
\hline
\end{tabular}


Tabel 3 Pengujian waterpump "Ph Up"

\begin{tabular}{|c|c|c|}
\hline No & $\begin{array}{c}\text { Hasil deteksi } \\
\text { sensor Ph }\end{array}$ & $\begin{array}{c}\text { Waterpump Ph } \\
\text { UP }\end{array}$ \\
\hline 1 & 3.32 & X \\
\hline 2 & 3.38 & X \\
\hline 3 & 3.35 & X \\
\hline 4 & 3.24 & $\checkmark$ \\
\hline 5 & 3.40 & $\checkmark$ \\
\hline 6 & 3.58 & $\checkmark$ \\
\hline 7 & 3.55 & $\checkmark$ \\
\hline 8 & 3.43 & $\checkmark$ \\
\hline 9 & 3.28 & $\checkmark$ \\
\hline 10 & 3.31 & $\checkmark$ \\
\hline
\end{tabular}

Keterangan :

- $\checkmark$ : Berhasil

- $\mathrm{x}$ : Tidak Berhasil.

Pengujian waterpump untuk menanggapi hasil deteksi sensor $\mathrm{Ph}$ bekerja dengan baik untuk mengalirkan $\mathrm{Ph}$ up dan $\mathrm{Ph}$ down kedalam akuarium dari dalam alat suntik, delay saat menyala yang di berikan kepada waterpump adalah satu detik dan mengalirkan $1 \mathrm{ml}$ cairan, Ketika sensor Ph melebihi batas atas waterpump akan mengalirkan ph down dari alat suntik ke dalam akuarium dan saat sensor ph melebihi batas bawah waterpump akan mengalirkan ph up kedalam akuarium untuk menjaga tingkat ph normal, kegagalan waterpump pada awal percobaan dikarenakan cairan ph up dan ph down belum memasuki waterpump sehingga tidak bisa di alirkan ke dalam akuarium.

\subsection{Pengujian Filter}

Pengujian Filter air dilakukan dengan cara memprogram Arduino sehingga dapat memerintahkan Filter air agar memompa air untuk menanggapi hasil dari sensor turbidity

Tabel 4 Pengujian Filter air

\begin{tabular}{|c|c|c|}
\hline No & $\begin{array}{c}\text { Hasil deteksi } \\
\text { Kekeruhan }\end{array}$ & $\begin{array}{c}\text { Filter } \\
\text { menyala }\end{array}$ \\
\hline 1 & 3.49 & $\checkmark$ \\
\hline 2 & 3.49 & $\checkmark$ \\
\hline 3 & 3.49 & $\checkmark$ \\
\hline 4 & 3.49 & $\checkmark$ \\
\hline 5 & 3.49 & $\checkmark$ \\
\hline 6 & 3.49 & $\checkmark$ \\
\hline 7 & 3.50 & $\checkmark$ \\
\hline 8 & 3.50 & $\checkmark$ \\
\hline 9 & 3.50 & $\checkmark$ \\
\hline 10 & 3.50 & $\checkmark$ \\
\hline
\end{tabular}

Keterangan :

- $\checkmark$ : Berhasil

$\cdot \mathrm{x}$ : Tidak Berhasil.

Berdasarkan Pengujian Filter Air diatas Keseluruhan ujicoba berhasil untuk menanggapi hasil deteksi sensor Turbidity Ketika mendeteksi tingkat kekeruhan sudah mencapai batas yang di tentukan dan bekerja dengan baik untuk menyaring air dan mengalirkan nya Kembali kedalam akuarium.

\subsection{Pengujian Heater}

Pengujian Heater dilakukan dengan cara memprogram Arduino sehingga heater dapat memanaskan elemen agar dapat menaikan suhu hasil dari respon sensor suhu

Tabel 5 Pengujian Heater

\begin{tabular}{|c|c|c|}
\hline No & Hasil deteksi Suhu & Heater menyala \\
\hline 1 & 20.69 & $\checkmark$ \\
\hline 2 & 20.69 & $\checkmark$ \\
\hline 3 & 20.69 & $\checkmark$ \\
\hline 4 & 20.69 & $\checkmark$ \\
\hline 5 & 20.69 & $\checkmark$ \\
\hline 6 & 20.69 & $\checkmark$ \\
\hline 7 & 20.75 & $\checkmark$ \\
\hline 8 & 20.69 & $\checkmark$ \\
\hline 9 & 20.69 & $\checkmark$ \\
\hline 10 & 20.69 & $\checkmark$ \\
\hline
\end{tabular}

Keterangan :

- $\checkmark$ : Berhasil

- $\mathrm{x}$ : Tidak Berhasil.

Hasil Pengujian Heater untuk menanggapi hasil deteksi sensor suhu Berhasil Ketika suhu yang di deteksi sudah mencapai batas bawah yang di tentukan dan bekerja dengan baik untuk Meningkatkan Suhu air yang ada di dalam akuarium, Heater akan mati secara otomatis Ketika suhu di dalam akuarium sudah mencapai titik suhu yang di tentukan

\subsection{Form Halaman Monitoring}

Pada gambar 7 terdapat halaman Monitoring untuk mengakses data sensor.

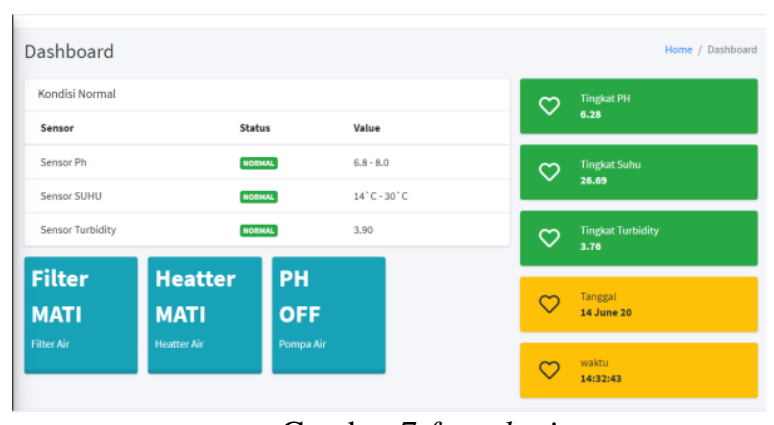

Gambar 7 form login

Setelah di halaman monitoring bisa lanjut ke halam history. Dihalaman History ini akan ditampilkan data riwayat dari hasil deteksi sensor yang telah di catat di database,tampilandari halaman riwayat yang ada di tampilkan pada gambar 8 di bawah. 


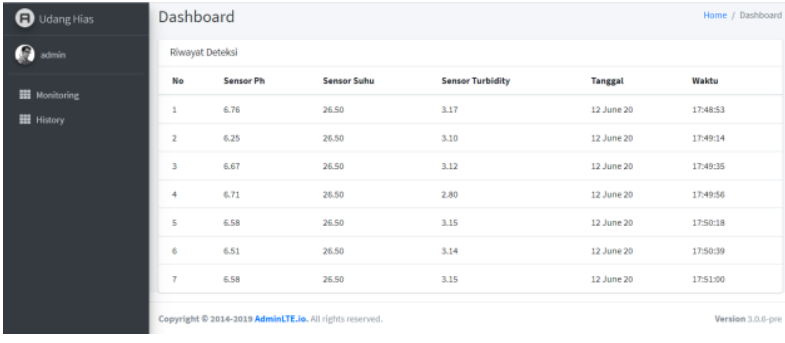

Gambar 8 halaman history

\subsection{Pengujian Fungsional}

Tabel 6 Pengujian fungsional

\begin{tabular}{|c|c|c|c|}
\hline \multirow[b]{2}{*}{ No. } & \multirow[b]{2}{*}{ Aspek Pengujian } & \multicolumn{2}{|c|}{ Web Browser } \\
\hline & & $\begin{array}{l}\text { Chrome } \\
\text { (78.0.3) }\end{array}$ & $\begin{array}{l}\text { Microsoft } \\
\text { Edge } \\
\text { (44.1.0) }\end{array}$ \\
\hline 1. & $\begin{array}{l}\text { Tampilan data } \\
\text { sensor dan bar } \\
\text { data pada halaman } \\
\text { Monitoring }\end{array}$ & $\checkmark$ & $\checkmark$ \\
\hline 2. & $\begin{array}{l}\text { Tampilan data } \\
\text { Riwayat pada } \\
\text { halaman History }\end{array}$ & $\checkmark$ & $\checkmark$ \\
\hline 3. & $\begin{array}{l}\text { Tampilan } \\
\text { responsif pada } \\
\text { halaman } \\
\text { monitoring }\end{array}$ & $\checkmark$ & $\checkmark$ \\
\hline 4. & $\begin{array}{l}\text { Tampilan } \\
\text { responsif pada } \\
\text { halaman History }\end{array}$ & $\checkmark$ & $\checkmark$ \\
\hline 5. & $\begin{array}{l}\text { Tampilan dan } \\
\text { fungsi login }\end{array}$ & $\checkmark$ & $\checkmark$ \\
\hline
\end{tabular}

Keterangan :

- $\checkmark$ : Berhasil

- $\mathrm{x}$ : Tidak Berhasil.

\section{KESIMPULAN DAN SARAN}

\subsection{Kesimpulan}

Berdasarkan beberapa pengujian yang telah dilakukan didapatkan kesimpulan :

1. Dari hasil pengujian sensor $\mathrm{pH}$ diketahui memiliki pembacaan tingkat keasaman yang cukup mendekati hasil

2. Dari hasil pengujian Esp 8266 alat sudah dapat berkomunikasi dan mengirimkan data dengan baik dapat dilihat dari 10 kali percobaan pengiriman data terdapat 8 data yang sukses dikirim kedalam server

3. Sensor suhu dan Sensor Tubidity dapat beroperasi optimal Ketika di aplikasikan dalam akuarium dengan ukuran( $(\mathrm{P} * \mathrm{~L} * \mathrm{~T}) 40 \mathrm{~cm} * 30 \mathrm{~cm}$ $* 30 \mathrm{~cm}$.
4. Website berjalan dengan baik pada web browser yang diujikan yaitu Google Chrome (78.0.3) dan Microsoft Edge (44.1.0) karena aplikasi merupakan website responsive yang dibuat menggunakan pemrograman PHP.

5. Menurut pengujian water pump dapat bekerja dengan mengalirkan $\mathrm{pH}$ up atau $\mathrm{pH}$ down untuk menstabilkan kondisi pH air

6. Menurut pengujian Filter air dan Heater dapat bekerja dengan baik sesuai fungsinya dengan menanggapi hasil deteksi sensor dan kondisi yang telah di tentukan

7. Alat secara keseluruhan bekerja dengan baik sesuai dengan desain awal yang dikerjakan.

\subsection{Saran}

Berdasarkan penelitian yang telah dilakukan, maka penulis dapat memberikan saran-saran untuk pengembangan selanjutnya antar lain :

1. Program masih terdapat kekurangan pada metode untuk melakukan penentuan karyawan terbaik yang masih belum dimplementasikan

2. Menambahkan buzzer sebagai peringatan apabila user berhasil melakukan absensi

3. Memberikan notifikasi berupa sms jika berhasil melakukan absensi kepada pimpinan perusahaan agar lebih memudahkan pimpinan perusahaan dalam memantau absensi kehadiran pegawai.

\section{DAFTAR PUSTAKA}

[1] Atmaja, G.C.T., Putrada, A.G. and Rakhmatsyah, A., 2018. Optimasi Tingkat Hidup Udang Crystal Red Dengan Menerapkan Metode Fuzzy Logic Berbasis Iot. eProceedings of Engineering, 5(2).

[2] Maulana, Y.Y., Wiranto, G. and Kurniawan, D., 2017. Online Monitoring Kualitas Air pada Budidaya Udang Berbasis WSN dan IoT. INKOM Journal, 10(2), pp.81-86.

[3] Rahayu, G., Sunarya, U. and Novianti, A., 2017. Rancang Bangun Web Server Untuk Pemantauan Budidaya Udang Vannamei Menggunakan Teknologi Iot. eProceedings of Applied Science, 3(3).

[4] Solihin, R., 2020, March. Peningkatan Budidaya Udang Galah Melalui Pemantauan dan Pengendalian Kualitas Air Secara Otomatis Berbasis IoT. In Prosiding-Seminar Nasional Teknik Elektro UIN Sunan Gunung Djati Bandung (pp. 275-286).

[5] Tadeus, D.Y., Azazi, K. and Ariwibowo, D., 2019. Model Sistem Monitoring pH dan Kekeruhan pada Akuarium Air Tawar berbasis Internet of Things. METANA, 15(2), pp.49-56. 